\title{
Democracia, justiça e 0 uso público da razão: reflexões sobre 0 debate entre Rawls e Habermas*
}

\author{
Democracy, justice, and the public use of reason: \\ reflections on the debate between Rawls and Habermas
}

\section{Renato Francisquini}

Doutorando em Ciência Política, bolsista do CNPq, Universidade de São Paulo - USP

e-mail: rfrancisquini@usp.br

Recebido: 26/09/2012

Aceito: 17/09/2013
RESUMO Este trabalho tem como tema central o debate entre Jürgen Habermas e John Rawls, e o seu foco recai principalmente sobre a discussão acerca do processo político democrático. Inicialmente se apresenta uma discussão sobre a teoria da justiça como equidade, buscando explorar os fundamentos para uma teoria da democracia deliberativa. Em seguida se expõem as críticas de Habermas a essa concepção, bem como as suas sugestões de aprimoramento. Na sequência discute-se a resposta de Rawls e a sua tentativa de estabelecer paralelos entre os dois projetos teóricos. Por fim, esboçamos tentativamente uma teoria da democracia deliberativa que seja tanto quanto possível coerente com o debate apresentado no início e que poderia ser subscrita por ambos os autores.

PALAVRAS-Chave: Teoria democrática; Deliberação pública; Justiça; Legitimidade.

ABSTRACT This paper has as its central issue the debate between Jürgen Habermas and John Rawls. It is focused mainly on the discussion regarding the democratic political process. Initially, a discussion about the theory of justice as fairness is presented, in order to explore the fundamentals of a theory of deliberative democracy. After that, the critics made by Habermas to this conception are exposed, as well as his suggestions for its development. Then there is a discussion regarding Rawls's response and his attempt to establish parallels between his and the German philosopher's theoretical projects. In the end, we tentatively outline a theory of deliberative democracy that is, as long as it is possible, coherent with the debate and that could be subscribed by both authors.

KEYWORDS: Democratic theory; Public deliberation; Justice; Legitimacy.

\footnotetext{
Gostaria de agradecer ao Lucas Petroni pela leitura atenta e os comentários às várias versões deste trabalho. A sua ajuda foi fundamental. Agradeço também ao Prof. Dênis Coitinho Silveira, que comentou a primeira versão do texto, apresentado no II Seminário Discente do Programa de Pós-graduação do Departamento de Ciência Política da USP. Por fim, mas não menos importante, aos editores e pareceristas anônimos da Teoria \& Pesquisa, que contribuíram sobremaneira para que este artigo se tornasse publicável.
} 


\section{Introdução}

Este trabalho tem como tema central o conceito de democracia - mais precisamente, de democracia deliberativa - presente nas obras de John Rawls e Jürgen Habermas. Toma-se como objeto de análise o debate entre os autores, promovido por Michael Kelly, então editor do Journal of Philosophy, em 1995. O foco neste debate, e não na obra dos autores de forma mais ampla, justifica-se pela importância que a discussão sobre o conceito de democracia, subjacente ao projeto teórico destes autores, ganha no mesmo. A oportunidade de um confronto direto de ideias pôs em relevo uma compreensão há muito disputada no campo da teoria política contemporânea, a saber, sobre a definição de autogoverno coletivo. Se a literatura produzida em torno da definição que toma as práticas argumentativas como sustentáculo das bases democráticas tendeu a distanciar o liberalismo igualitário da teoria discursiva, o trabalho que ora se inicia caminha na direção inversa: a partir do exposto no debate de 1995, argumentar-se-á que os autores partilham um campo comum no que concerne ao conceito de democracia.

De início, portanto, considera-se que Rawls e Habermas, mesmo lançando mão de uma linguagem distinta, se situam dentre os proponentes de uma teoria deliberativa da democracia ${ }^{1}$. Mas o que se quer dizer com isso? Porque situar dois projetos teóricos tão distintos dentro de uma mesma vertente (deliberativa) da teoria política ${ }^{2}$ ? Gostaria de argumentar que, embora por muito tempo a separação entre filosofia analítica e continental tenha distanciado dois projetos teóricos cuja base remonta à filosofia prática de Kant, Rawls e Habermas permaneceram suficientemente próximos para que os seus desacordos sejam instrutivos, sobretudo nos estudos de filosofia e teoria política (McCarthy, 1994: 45). As críticas recíprocas nos textos de 1995 resultaram em importantes clarificações e desenvolvimentos nas teorias de cada um. Habermas permitiu que Rawls tornasse mais explícita a sua noção de justificação pública; este, por sua vez, influenciou o início do desenvolvimento de uma visão mais positiva daquele sobre a importância dos discursos éticos para a integração social

\footnotetext{
${ }^{1}$ Este é um dos pontos que quero explicitar e defender no texto. Reconheço que um autor do peso de um Álvaro de Vita discorda dessa visão (no que se refere a John Rawls, embora o próprio Rawls o afirme em seus trabalhos mais recentes) e tentarei no que se segue argumentar, a partir dos esclarecimentos apresentados pelos autores no debate do Journal of Philosohpy, em prol de um conceito de democracia que, acredito, poderia ser subscrito por Rawls e Habermas.

2 Ademais, Rawls não figura sequer entre os autores que tradicionalmente se inclui dentro da teoria democrática.
}

(Finlayson e Freyenhagen, 2011: 2). Ademais, embora tenham se valido de abordagens diferentes, eles se debruçaram sobre problemas de ordem semelhante e as suas conclusões foram, por vezes, complementares, não contraditórias ${ }^{3}$. Nos textos de 1995 - e mesmo após esse debate -, eles parecem mover-se em direção a um campo de argumentação compartilhado: ambos concordam que a filosofia política não é uma teoria moral aplicada, rejeitam um realismo político segundo o qual princípios morais e motivações seriam irrelevantes para a política, e tornam a ideia de legitimidade elemento central de seus projetos teóricos.

O ponto de partida de uma concepção deliberativa de democracia é o contexto de justificação, típico das sociedades modernas, que se estabelece pelo fato do pluralismo: o fato de que a cultura política pública em sociedades democráticas será inevitavelmente caracterizada por uma diversidade de concepções religiosas, filosóficas e morais abrangentes, que é resultado do exercício da razão humana sob instituições livres. As concepções abrangentes do bem são fruto do livre exercício da razão prática e são questões sobre as quais pessoas razoáveis discordam. Ademais, essa literatura considera a possibilidade de consensos sustentados por razões suficientes (ou que respeitem o princípio de não-rejeição) para todos, independentemente de sua concepção abrangente do bem.

Tendo em vista tal reconhecimento, a teoria deliberativa busca sustentar os fundamentos normativos de uma comunidade política de iguais no consentimento público e esclarecido de cidadãos livres e iguais. Nesse sentido, a vertente deliberativa da teoria democrática aborda o problema da democracia a partir de uma perspectiva que valoriza uma avaliação crítico-normativa, discursiva, das relações de poder. Ou seja, o contexto de justificação submete as decisões políticas a um critério de legitimidade racional, que se caracteriza pela possibilidade de reconhecimento por todos os cidadãos a partir de seu juízo público. Afirma-se, portanto, a viabilidade de um consenso baseado em um acordo em termos razoáveis entre pessoas livres e iguais, a despeito dos desacordos

\footnotetext{
3 Até meados da década de 1980 e o início da década de 1990, a ética do discurso dirigia-se à correção moral que governa a estrutura básica a partir de uma teoria geral, enquanto a justiça como equidade o fazia a partir de uma teoria do político. Após o lançamento de $O$ Liberalismo Político e Direiro e Democracia, a situação modificou-se e a aplicação da moralidade à política tornou-se mais complexa. Habermas passou a aceitar que a correção moral não era suficiente para sustentar a legitimidade política. Rawls, por sua vez, tornou mais claro que a justiça como equidade não era uma teoria geral que se dirigia à correção das ações individuais (Finlayson e Freyenhagen, 2011: 7).
} 
provenientes da pluralidade de concepções divergentes sobre a boa vida. A ideia de lei legítima, nesse caso, não se subordina à moralidade nem tampouco aos valores compartilhados por uma comunidade ou concepções tradicionais do bem comum. Antes, ela está ancorada na possibilidade de aceitação por todos mediante o uso público da razão. Portanto, o Estado constitucional, na perspectiva deliberativa, tem uma relação interna com os procedimentos democráticos de deliberação.

Ao tomar uma ideia abstrata sobre o conceito de democracia - tão abstrata como deve ser, sugere Joshua Cohen -, seria possível dizer que

[...] a ideia fundamental de legitimidade política democrática é a de que a autorização para o exercício do poder estatal deve emanar das decisões coletivas dos membros iguais da sociedade que é governada por aquele poder (Cohen, 1998: 185, tradução livre; ênfase no original $)^{4}$.

As diferentes concepções sobre a democracia se sustentam em entendimentos distintos sobre questões como o pertencimento à cidadania e o que torna uma decisão coletiva. A teoria deliberativa, ao contrário de outras concepções, afirma que a exigência de mútuo respeito entre os cidadãos não se realiza pela igual consideração pelo interesse de $\operatorname{todos}^{5}$, mas pelo oferecimento de justificações para o exercício do poder coletivo que possam ser aceitas - ou não rejeitadas - como razoáveis ${ }^{6}$ por todos. Nesse sentido, considera-se que o caráter coletivo de uma decisão advém do fato de que os arranjos sociais e políticos (1) facilitam a livre argumentação, oferecendo, por exemplo, condições favoráveis à expressão, à participação e à associação, de modo a assegurar que os cidadãos sejam tratados como iguais no processo político argumentativo; e (2) amarram a autorização ao exercício do poder coercitivo da sociedade a tal discussão pública, mediante a construção de uma estrutura institucional que favoreça a responsividade e a accountability do poder político, estabelecendo eleições periódicas, transparência das decisões legislativas etc.

Nas formulações teóricas que se consolidaram no modelo normativo da democracia deliberativa são feitos determinados julgamentos sobre as

\footnotetext{
${ }^{4}$ No original: "[...]the fundamental idea of democratic, political legitimacy is that the authorization to exercise state power must arise from the collective decisions of the equal members of a society who are governed by that power".

5 Cf. Przeworski (2010: 15-21).

${ }^{6}$ Recaem sob a rubrica do razoável, segundo Rawls (2011b), aquelas razões que não exigem do poder coercitivo da sociedade a imposição de uma concepção abrangente do bem.
}

características do processo político democrático, especialmente no sentido de distinguir esse processo da barganha, dos contratos e de outras formas de interação típicas do mercado - o que lança luz sobre a necessidade de considerações a respeito das vantagens coletivas e sobre a formação das preferências dos participantes durante o processo. Nessa concepção, é comum que se estabeleça uma relação entre a noção de associação democrática e ideais de autonomia e do bem comum (Gutmann e Thompson, 2004).

Embora estejam de acordo quanto às formulações acima, permanece entre Rawls e Habermas uma controvérsia referente à definição da instância apropriada para a justificação normativa da deliberação (Werle, 2004: 139-40). No debate promovido pelo Journal of Philosophy fica claro que tais divergências se relacionam, sobretudo, ao entendimento distinto sobre as características dos dispositivos de representação e a associação entre os contextos de justificação teórica e prática. $\mathrm{O}$ artigo buscará discutir os pontos centrais do debate, prestando especial atenção à possibilidade de reconciliação entre estes projetos no que concerne às características centrais do conceito de democracia apresentado acima. $\mathrm{O}$ argumento central que será defendido é o de que o liberalismo político rawlsiano, não menos do que a teoria do discurso habermasiana, pressupõe a prática comunicativa e a justificação pública como elementos primordiais de uma sociedade democrática. Pretende-se demonstrar, nesse sentido, que os princípios de justiça não representam uma restrição à autodeterminação dos cidadãos.

Procurando lidar com as questões envolvidas no debate, embora sem a preocupação de esgotar o horizonte abrangente destes projetos teóricos, o trabalho irá percorrer o seguinte caminho: inicialmente se apresenta de maneira breve a teoria da justiça como equidade e a sua relação com a democracia (I); num segundo momento sublinham-se as críticas de Habermas à teoria da justiça como equidade, sobretudo às questões pertinentes ao uso público da razão e a relação entre as liberdades individuais e a autodeterminação (II); em seguida discute-se a réplica de Rawls, buscando destacar a compreensão do autor sobre as críticas recebidas e o esforço para esclarecer a sua noção de justificação pública dos princípios de justiça (III); por fim, procura-se demonstrar que os projetos teóricos em questão compartilham um conceito de democracia deliberativa cujas características se sustentam em uma compreensão comum sobre o contexto de justificação das sociedades modernas. 
A teoria da justiça como equidade ${ }^{7}$, de John Rawls, representou um salto paradigmático na filosofia política moderna. $\mathrm{O}$ autor se propôs a elaborar uma concepção política de justiça para as sociedades democráticas ${ }^{8}$, partindo, para tanto, de uma concepção filosófica sobre a democracia constitucional. Nesse esforço, busca explorar as razões pelas quais os cidadãos de uma sociedade democrática, dado o fato do pluralismo, poderiam considerar razoável uma concepção de justiça política e social.

Rawls buscou construir uma concepção de justiça capaz de incorporar tanto as razões morais do agir neutras em relação ao agente quanto as razões relativas ao agente ${ }^{9}$. Nesse sentido, ele busca apresentar uma visão clara das principais características estruturais da concepção de justiça implícita na tradição contratualista. A justiça como equidade, assim como as demais visões contratualistas, tem duas partes: uma correspondente à interpretação da situação inicial e do problema da escolha colocada nesse contexto, e outra ao conjunto de princípios que seria aceito consensualmente pelas partes do acordo (Rawls, 2008: XLIII-IV).

O ponto de partida do autor é a ideia kantiana de igual valor intrínseco dos indivíduos, ou seja, o principio segundo o qual todas as pessoas são fins em si mesmas e devem ser a unidade última de preocupação moral ${ }^{10}$. Uma sociedade democrática (ou uma sociedade justa), na formulação rawlsiana, é aquela em que as instituições sociais, econômicas e políticas tratam os cidadãos como membros moralmente iguais e oferecem a cada um os direitos, liberdades e oportunidades necessários à persecução de seus fins e convicções morais (Nagel, 2003: 70-1).

Cada um dos ideais a que o autor busca adequar a sua teoria - liberdade, igualdade e fraternidade - corresponde a um dos componentes da sua concepção de justiça. Uma sociedade seria

\footnotetext{
Sabemos que o projeto teórico rawlsiano, desde Uma Teoria da Justiça, de 1971, passou por inúmeras reformulações, através das quais Rawls reviu certos pressupostos e mesmo deixou de subscrever outros. Neste capítulo apresento as principais ideias tais como acredito que Rawls, caso fosse possível, subscreveria hoje a partir de seus últimos trabalhos. Apenas eventualmente iremos ressaltar as distinções entre uma versão e outra de sua teoria da justiça como equidade, o faremos quando considerarmos necessário ao desenvolvimento do nosso argumento.

${ }^{8}$ Sociedades que se estabeleceram como um sistema equitativo de cooperação social.

${ }^{9}$ Cf. Vita (2000a: 15-6)

${ }^{10}$ Nas palavras do autor: "Cada pessoa possui uma inviolabilidade fundada na justiça que nem mesmo o bem-estar da sociedade como um todo pode ignorar. Por essa razão, a justiça nega que a perda da liberdade de alguém se justifique por um bem maior partilhado por outros" (2008: 4)
}

bem-ordenada quando regulada por uma concepção pública de justiça cujos princípios são aceitos como razoáveis por todos - os cidadãos aceitam, e sabem que os demais também aceitam, princípios razoáveis de justiça política; a estrutura básica da sociedade regula-se de acordo com os mesmos. Numa ordenação como essa, os homens, embora não deixem de fazer exigências mútuas eventualmente excessivas, reconhecem um ponto de vista a partir do qual as suas reivindicações possam ser julgadas. O objeto primário da justiça, nessa perspectiva, é a estrutura básica da sociedade ou, em outras palavras,

[...] a maneira pela qual as principais instituições políticas e sociais de uma sociedade se organizam em um sistema de cooperação social, bem como a maneira pela qual atribuem direitos básicos e deveres e regulam a divisão das vantagens provenientes da cooperação social ao longo do tempo [...] (Rawls, 2003: 10, tradução livre) ${ }^{11}$.

O papel de uma concepção política de justiça não é o de especificar precisamente como cada questão deve ser resolvida, mas, antes, o de formular um enquadramento a partir do qual elas possam ser examinadas.

Dado o fato do pluralismo valorativo, os termos da cooperação social devem ser dados por um acordo entre os que estarão submetidos à estrutura básica que será regulada por tais termos, pois seria vedado qualquer acordo baseado em uma autoridade moral que se sustenta em uma concepção abrangente do bem - assim como não seria possível um consenso em torno de uma ordem de valores ou os ditados de quaisquer leis naturais. É importante, portanto, que ela possa ser aceita voluntariamente por cada indivíduo submetido a tal ordenação. A partir de $O$ Liberalismo Político, essa premissa passa a sustentar a necessidade de uma argumentação moral que leva à defesa da prioridade da justiça sobre o bem e de uma concepção política que se sustenta por si mesma (free standing), que poderia ser objeto de um consenso sobreposto. Essa seria uma distinção fundamental entre a sociedade como um todo e as diversas comunidades que presumivelmente irão se formar em seu interior.

Na justiça como equidade, uma sociedade política democrática não dispõe de tais valores e fins compartilhados, além daqueles que se inserem na, ou estão conectados à, própria concepção política de justiça. Os cidadãos de uma sociedade

\footnotetext{
${ }^{11}$ No original: "The way in which the main political and social institutions of society fit together into one system of social cooperation, and the way they assign basic rights and duties and regulate the division of advantages that arises from social cooperation over time".
} 
bem-ordenada afirmam a constituição e seus valores políticos tais como impressos em suas instituições, e eles compartilham o dever de oferecer, uns aos outros, justiça, da forma como os arranjos sociais o exigem (Rawls, 2003: 20, tradução livre) $)^{12}$.

Rawls (2003) parte, portanto, da premissa segundo a qual,

[...] o poder politico é sempre o poder coercitivo aplicado pelo Estado e pelo seu aparato de execução (enforcement); mas, em um regime constitucional, o poder político é ao mesmo tempo o poder de cidadãos livres e iguais como um corpo coletivo [...] (p. 40, tradução livre $)^{13}$.

O liberalismo político sustenta que uma concepção de justiça deve ser uma concepção política que, quando satisfeita, permite que se diga que o poder político é legítimo se, e somente se, é exercido de acordo com uma Constituição cujos princípios básicos as pessoas, tomadas como razoáveis e racionais, poderiam endossar à luz de sua razão humana comum. É um desiderato adicional que as questões legislativas que dizem respeito ou estão próximas dessas questões constitucionais básicas sejam também definidas por valores que possam ser similarmente aceitáveis. Uma concepção política de justiça formula esses valores e os princípios compartilhados tornam a razão pública; as liberdades de expressão e pensamento, por seu turno, a tornam livre ${ }^{14}$.

O projeto rawlsiano apresenta uma ampla discussão sobre as exigências da justiça e sobre como deve se desenhar uma sociedade justa, além de como a justiça seria coerente com as concepções de bem dos cidadãos que vivem em tal sociedade. Contudo, ele não discute em profundidade o processo político democrático. Isto foi interpretado por parte da literatura como a dispensa de uma preocupação central com os processos de argumentação pública, de mobilização política e competição eleitoral, com as decisões legislativas e a administração política em geral ${ }^{15}$. Essa

\footnotetext{
${ }^{12}$ No original: "In justice as fairness a democratic political society has no such shared values and ends apart from those falling under or connected with the political conception of justice itself. The citizens of a well-ordered society affirm the constitution and its political values as realized in their institutions, and they share the end of giving one another justice, as society's arrangements require".

${ }^{13}$ No original: "Political power is always coercive power applied by the state and its apparatus of enforcement; but in a constitutional regime political power is at the same time the power of free and equal citizens as a collective body".

${ }^{14}$ Como se pode notar, no entanto, uma concepção política de justiça não formula valores que resolvam todas as questões legislativas. Isto não é possível nem tampouco desejável.

${ }^{15}$ De certa forma, é a isso que Habermas se refere em sua crítica à autoridade filosófica que vê impressa na teoria política rawlsiana.
}

relativa desatenção à democracia - e à política de modo geral - pode deixar a impressão de que Rawls desconsidera o tema por subordiná-lo a uma concepção de justiça defendida através da argumentação filosófica, que só poderá ser implementada no mundo real por juízes e administradores afastados da política concreta. Nesse sentido, pode surpreender quando, já no prefácio à primeira edição de Uma Teoria $d a$ Justiça, Rawls afirma que a sua concepção de justiça como equidade é a concepção que "[...] mais se aproxima dos nossos juízos ponderados acerca da justiça e constitui o alicerce moral mais apropriado à sociedade democrática [...]" (2008: XLV, grifo nosso).

Embora não seja uma teoria da democracia no sentido tradicionalmente atribuído a este campo da teoria política, a justiça como equidade figura como uma importante contribuição para o pensamento democrático. Senão por outros motivos, porque um regime político democrático é, por si mesmo, um requisito fundamental da justiça ${ }^{16}$. A justiça como equidade associa-se inextricavelmente à teoria democrática, pois os seus princípios (a) atribuem aos indivíduos um direito igual à participação nas decisões políticas - o que, portanto, requer um regime democrático como uma questão de justiça básica; (b) se dirigem aos cidadãos como pessoas morais livres e iguais, e o seu conteúdo é estruturado por este entendimento público; e (c) se destinam a servir como guia para a argumentação e o julgamento públicos por parte dos membros de uma sociedade democrática no exercício de seus direitos políticos ${ }^{17}$.

Ainda que trace uma linha divisória entre a justiça e a legitimidade democrática, a concepção de justiça como equidade relaciona uma à outra ao menos de três maneiras: (1) o conteúdo da noção mais razoável de justiça requer um sistema político democrático; (2) as bases dos princípios se assentam na ideia de sociedade democrática, entendida como uma sociedade de iguais, e o conteúdo dos princípios expressam essa ideia; e (3) o papel dos princípios é guiar os julgamentos dos membros de uma sociedade democrática apresentando normas fundamentais de argumentação política pública adequadas à sua posição de igualdade ${ }^{18}$.

Rawls assume, portanto, a política democrática como uma arena de argumentação, no que se distancia

\footnotetext{
${ }^{16}$ Não estamos afirmando, com isso, que democracia e justiça sejam e mesma coisa, nem tampouco que uma seja instrumento para a realização da outra. Concordamos, nesse caso, com Vita (2000b: 5), que afirma que a "democracia e a justiça têm ambas valor intrínseco, e não são redutíveis uma à outra".

${ }^{17}$ Cf. Rawls (2011b).

${ }^{18}$ Para uma discussão sobre a relação entre justiça e democracia em Rawls, cf. Cohen (2003).
} 
das concepções que a entendem como uma espécie de "competição domesticada" por poder, agregação justa de interesses ou a expressão de compromissos culturais compartilhados ${ }^{19}$. Ele se propõe a articular a visão mais razoável da justiça a partir da qual os cidadãos e os seus representantes possam guiar seus julgamentos no exercício da deliberação política. Assim, seria possível dizer que a crítica à ausência da "política" na justiça como equidade vem de uma visão pouco simpática à compreensão da política democrática como uma troca de razões entre cidadãos livres e iguais - ou como uma democracia deliberativa. Rawls constrói, portanto, uma concepção de democracia na qual cabe aos cidadãos e seus representantes a proposição e a defesa de leis e políticas tendo como referência razões derivadas de uma concepção de justiça que eles esperam que outros cidadãos poderão razoavelmente aceitar (Cohen, 2003: 101-2). A existência de princípios de justiça, tal como estabelecidos pela justiça como equidade não elimina os desacordos políticos e, portanto, a deliberação. Antes, eles a pressupõem. Controvérsias sobre questões como a preservação ambiental ou temas econômicos mais complexos emergirão de forma perene dentro dos arranjos institucionais elaborados a partir dos princípios de justiça. Além disso, mesmo a aplicação destes princípios se apresenta como uma questão aberta à discussão e ao julgamento, como no caso da escolha de princípios constitucionais que assegurem a proteção dos direitos e liberdades individuais, ou nas decisões a respeito da estrutura legal mais adequada à garantia da igualdade de oportunidades ${ }^{20}$. Por fim, ressalte-se que, a partir de fins da década de 1980, em especial com a publicação de $O$ Liberalismo Político, Rawls destaca que a justiça como equidade é uma dentre outras concepções razoáveis de justiça a que os cidadãos, a partir de seu juízo público, poderiam aderir e defender no fórum político público.

\section{II}

As objeções de Habermas se dirigem, em especial, a três pontos do projeto rawlsiano, quais sejam: (i) a concepção do dispositivo de representação; (ii) a separação entre os critérios de aceitabilidade racional

\footnotetext{
${ }^{19}$ Estas seriam posições defendidas, respectivamente, por concepções minimalistas, agregativas e comunitaristas

${ }^{20}$ Segundo Rawls, a proteção aos direitos e liberdades básicas está associada inextricavelmente ao "princípio de participação", segundo o qual "todos os cidadãos devem ter o direito igual a tomar parte em e determinar os resultados dos processos constitucionais que estabelecem as leis que devem cumprir" (apud Cohen, 2003: 89, tradução nossa)
}

e de aceitação factual dos princípios de justiça; e (iii) o equilíbrio e a relação entre as autonomias pública e privada. Segundo o autor alemão, a forma como Rawls concebe estas questões o leva à construção de um estado constitucional que estabelece a primazia dos direitos individuais (ou as "liberdades dos modernos", no sentido de Constant) sobre o princípio democrático de legitimidade (ou as "liberdades dos antigos"), o que impediria a justiça como equidade de harmonizar as liberdades fundamentais com aquilo que Rawls denomina de o valor equitativo das liberdades políticas (Habermas, 1995: 109-10).

\section{1}

A primeira objeção de Habermas tem a ver com a forma como Rawls concebe o seu dispositivo de representação. A posição original foi descrita como uma situação em que representantes, racionalmente motivados, sob constrangimentos que garantem a imparcialidade, fazem julgamentos sobre questões práticas. A concepção de autonomia plena é, portanto, reservada aos cidadãos que vão viver sob as instituições construídas a partir dos princípios escolhidos na posição original. Para a construção deste contexto, Rawls teria separado o conceito de autonomia política em dois elementos: de um lado, as características moralmente neutras das partes que buscam a sua vantagem racional; de outro, os constrangimentos situacionais moralmente substantivos sob os quais as partes escolhem os princípios para um sistema justo de cooperação. As partes, como representantes fictícios dos cidadãos reais, não precisam considerar as questões de um ponto de vista moral - ou elas não precisam ser "razoáveis", o que as levaria a considerar o que é do interesse de todos -, pois a imparcialidade é garantida de antemão mediante o dispositivo do véu de ignorância (Habermas, 1995: 111).

Para Habermas, não seria plausível uma defesa consistente da posição de que cidadãos plenamente autônomos sejam representados por partes a quem falta esse mesmo tipo de autonomia. Na posição original, a razoabilidade das pessoas morais é substituída pelas restrições impostas pelo desenho racional do arranjo fictício. Ao mesmo tempo, porém, supõe-se que as partes compreendam os interesses de ordem mais elevada dos seus representados: é dizer, as partes entendem e levam a sério as implicações de uma autonomia que lhes é negada. Segundo ele, isso seria plausível no caso de interesses próprios relacionados e/ou de uma concepção do bem conhecida desde o início; contudo, o significado de concepções de justiça dificilmente permaneceria intocado pela perspectiva 
de agentes racionais autointeressados (Habermas, 1995: 112-3).

Essas reflexões procuram mostrar que a capacidade de tomar decisões racionais pode não ser suficiente para que as partes, na posição original, compreendam os interesses de ordem mais elevada daqueles que representam ou para defender a ideia de que os direitos se sobrepõem aos objetivos coletivos. Para Habermas, os ganhos potenciais de retomar o imperativo categórico kantiano a partir de um procedimento intersubjetivo aplicado, no qual Rawls insere as condições de participação (como a igualdade entre as partes) e as características situacionais (como o véu de ignorância), se perdem justamente pelas restrições impostas pelo contexto. A posição original seria, portanto, inadequada para descrever o ponto de vista do julgamento imparcial de princípios deontológicos de justiça, pois está carregada de considerações morais substantivas:

Eu acredito que Rawls poderia ter evitado as dificuldades associadas ao desenho de uma posição original se houvesse operacionalizado o ponto de vista moral de uma maneira diferente, a saber, se houvesse mantido a concepção procedimental de razão prática livre de conotações substantivas, desenvolvendo-a em uma forma estritamente procedimental (Habermas, 1995: 116, tradução livre) $)^{21}$.

Portanto, Habermas argumenta que o véu de ignorância, ao limitar de início o campo de visão das partes na posição original, restringiria o julgamento sobre os princípios de justiça com os quais deverão concordar cidadãos livres e iguais, a despeito da possibilidade de compreensões distintas sobre si mesmos e o mundo. Para ele, Rawls aceita um duplo ônus da prova: o véu de ignorância se estende a todos os pontos de vista particulares que poderiam desequilibrar o julgamento imparcial e, ao mesmo tempo, se restringe às questões normativas, sob o risco de ser desqualificado como candidato a uma concepção de bem, que poderá ser aceita ou não sob as condições do pluralismo moral. Para cumprir essa segunda condição, a teoria deverá arcar com o ônus de antecipar ao menos algumas das informações (de todos os conteúdos normativos que poderiam nutrir o autoconhecimento compartilhado de cidadãos livres e iguais) de que aliviou as partes no desenho da posição original. A imparcialidade pretendida pela posição

\footnotetext{
${ }^{21}$ No original: "I believe that Rawls could avoid the difficulties associated with the design of an original position if he operationalized the moral point of view in a different way, namely, if he kept the procedural conception of practical reason free of substantive connotations by developing it in a strictly procedural manner".
}

original só seria garantida, segundo Habermas, caso as concepções normativas básicas empregadas na sua construção pudessem resistir à revisão crítica sob a luz das experiências futuras significativas e aos processos de aprendizagem - o que não seria possível no modelo de justificação que se constrói a partir da posição original (Habermas, 1995: 118).

O principal questionamento de Habermas, nesse caso, refere-se ao fato de a justificação dos princípios de justiça se concentrar menos na deliberação que ocorre no dispositivo de representação do que nas intuições e conceitos básicos que guiam a construção da posição original. Rawls teria inserido conteúdos normativos no procedimento de justificação, em especial aqueles que se referem às duas capacidades da pessoa moral. Segundo Habermas (1995), o conceito de pessoa moral que sustenta a concepção de cooperação justa entre cidadãos autônomos exige uma justificação anterior - assim como é preciso demonstrar que essa concepção é neutra em relação a visões de mundo conflitantes, antes e depois de erguido o véu de ignorância. Isso representaria certa indefinição sobre a natureza do que precisa ser justificado e sobre como a pretensão de validade da teoria deve ser compreendida.

\section{2}

A segunda objeção, relacionada à primeira, se dirige aos critérios de aceitabilidade da teoria rawlsiana. Segundo Habermas (1995), não fica claro em que medida Rawls (2008) relaciona ou associa a aceitabilidade racional à aceitação de fato dos princípios de justiça na esfera pública política. Ao discutir, ainda em Uma Teoria da Justiça, as questões relativas à estabilidade de uma sociedade constituída de acordo com os dois princípios da justiça como equidade, Rawls procura responder à seguinte questão: uma sociedade constituída a partir dos princípios de justiça como equidade seria capaz de gerar as motivações necessárias à estabilidade política e social mediante a socialização política de seus membros? Isto é: levando a sério o fato do pluralismo, Rawls procura esclarecer em que medida a concepção teórica de justiça proposta por ele estaria dentro da "arte do possível". Parece fundamental, para tanto, que a concepção de pessoa moral seja neutra em relação às diversas filosofias de vida ${ }^{22}$ - i.e. seria preciso mostrar que os princípios da justiça como equidade seriam objeto de um consenso sobreposto. No entanto,

\footnotetext{
${ }^{22}$ Para uma crítica à concepção de pessoa do liberalismo rawlsiano, cf. Sandel (1982)
} 
Rawls não deixa explícito se o consenso sobreposto teria um caráter cognitivo, dirigido à explicação da condição necessária à estabilidade social, ou se teria apenas caráter instrumental.

Nesse sentido, Habermas (1995) considera inadequada a distinção, proposta por Rawls, entre questões de justificação teórica e questões de aceitação pública. O teste de aceitabilidade, segundo Habermas, não pode ser feito de forma imanente. Em uma concepção de democracia deliberativa, a teoria, de forma geral, deverá estar sujeita à crítica dos cidadãos no fórum da razão pública. Ao situar a questão da estabilidade no plano teórico, o consenso sobreposto torna-se apenas uma contribuição funcional da teoria da justiça para a institucionalização pacífica da cooperação social, na qual o valor intrínseco de uma teoria justificada deve ser pressuposto de antemão. Em uma perspectiva que o autor denomina "funcionalista", a possibilidade de a teoria conquistar o consentimento público perde o valor epistêmico que é caro à própria teoria. $\mathrm{O}$ consenso sobreposto torna-se apenas um índice de utilidade, perdendo a capacidade de confirmar os critérios de validade da teoria.

Mas este não é decerto o objetivo de Rawls, admite Habermas. O que o autor deseja, ao denominar a sua concepção "política", é justamente tornar menos nítida a distinção entre a justificação racional, no plano da teoria, e a aceitação de fato de uma concepção política de justiça, no fórum público. Nesse sentido, Habermas considera que seria mais proveitoso fazer uma distinção mais clara entre essas questões. Segundo ele, seria necessário permitir uma relação epistêmica entre a validade da teoria e a previsão de que ela alcance a neutralidade frente às concepções abrangentes do bem - o que, por sua vez, será confirmado apenas no discurso público. Assim, o efeito estabilizador do consenso sobreposto seria explicado em termos cognitivos, ou seja, nos termos da confirmação de que a justiça como equidade é uma concepção neutra (Habermas, 1995: 119-23).

Rawls (2008) considera inadequado tanto o realismo moral quanto o ceticismo de valores. Portanto, pretende que a sua própria teoria se configure enquanto uma forma de obrigatoriedade racional fundada no reconhecimento intersubjetivo - sem referência, contudo, a um significado epistêmico. Para tanto, introduz a ideia de razoabilidade como um predicado à concepção de verdade. Essa questão sugere ao menos duas alternativas para a compreensão do caráter complementar do predicado: ou bem se entende o "razoável" no plano da razão prática, como um sinônimo de "verdade moral", ou bem se toma o "razoável" no mesmo senso de "ponderado", em relação a visões discutíveis cuja solução definitiva não se encontra no presente, e, vale dizer, provavelmente não se encontrará também no futuro. Mas o consenso sobreposto, afirma Habermas, não pode ser o sustentáculo da justiça. O razoável, no sentido prático, deve ser necessariamente independente e ter prioridade sobre as noções éticas de verdade.

De acordo com Habermas (1995), Rawls entende o significado de razão prática tendo por referência duas dimensões: a dimensão deontológica da validação normativa e a dimensão pragmática da esfera pública - o uso público está, assim, de certa forma, inscrito na razão. Tanto as objeções de Habermas ao desenho da posição original, quanto as relativas à assimilação dos critérios de validade aos de aceitação, apontam na mesma direção: ao sujeitar os indivíduos racionais da posição original aos constrangimentos procedimentais razoáveis, a teoria rawlsiana segue dependente de suposições normativas substantivas; assim também, ao costurar a teoria universalista da justiça às questões políticas de estabilidade - através do consenso sobreposto -, ela compromete o seu status epistemológico. Ambas as estratégias são perseguidas em detrimento de uma concepção puramente procedimental, como Habermas considera a sua própria teoria. Para Habermas, Rawls satisfaria de forma mais elegante o ônus da prova se desenvolvesse sua concepção substantiva a partir de um procedimento baseado estritamente no uso público da razão. Em sua visão, o ponto de vista moral está implícito na constituição socioontológica da prática pública da argumentação, que inclui as relações de reconhecimento mútuo implicadas no discurso racional com as quais os participantes têm de concordar ${ }^{23}$.

\section{II.3}

No terceiro plano, Habermas lança luz sobre a relação estabelecida pelo liberalismo rawlsiano entre os direitos liberais básicos e o exercício das liberdades políticas. Rawls, como Kant e Rousseau, subscreve a intuição segundo a qual as liberdades individuais e os direitos de participação devem derivar da mesma fonte, que é a autonomia moral e política. Em tal perspectiva, os direitos liberais não são impingidos na prática da autodeterminação como restrições extrínsecas a ela, nem aparecem como instrumentos para o seu exercício. Todavia, Habermas (1995)

\footnotetext{
${ }^{23}$ Como veremos adiante, Rawls afirma que uma teoria da justiça construída exclusivamente em termos procedimentais não seria suficientemente estruturada. Além disso, a própria divisão entre procedimento e substância pode ser problemática. Cf. Gutmann e Thompson (2004)
} 
considera que "os dois estágios de justificação"24 dariam certa prioridade aos direitos liberais, deixando o processo democrático em um plano inferior. Ainda que se parta de uma ideia de autonomia política que é modelada ao nível da posição original, essa ideia é trazida apenas seletivamente ao nível institucional do processo político democrático de formação da vontade democrática. A autonomia política, garantida no primeiro nível da teoria - a saber, na posição original -, não se manifestaria da mesma forma no seio da sociedade constituída de maneira justa. Nesse sentido,

Quanto mais se levanta o véu de ignorância e quanto mais os cidadãos de Rawls tornam-se pessoas de carne e osso, mais profundamente eles se encontram sujeitos a princípios e normas que foram antecipados pela teoria e tornaram-se institucionalizados fora de seu controle (Habermas, 1995: 128, tradução livre $)^{25}$.

Nessa perspectiva, a fundação da constituição democrática não se repete sob as condições de uma sociedade justa constituída previamente, e o processo de realização dos direitos básicos não pode ser assegurado de forma contínua. Não seria possível aos cidadãos, portanto, vivenciar este como um processo inacabado e em aberto, como exigem as circunstâncias históricas cambiantes. O fato de não ser possível aos cidadãos conceber a constituição como um projeto faria com que o uso público da razão não tenha a importância que deveria ter o exercício da autonomia política, ficando relegado meramente à condição de garantia da preservação da estabilidade política. A separação rígida entre as identidades política e não-pública dos cidadãos, representada pelas restrições que os direitos liberais básicos impõem ao exercício da autodeterminação - e, com isso, à esfera do político - é promovida, desde o início e, portanto, antes do processo de formação da vontade política.

Assim, a esfera dos valores políticos, em Rawls (2008), seria dada de antemão, pois apenas em referência a tais valores seria possível dividir a pessoa moral entre a sua identidade pública, de cidadão, e a sua identidade privada, de indivíduo particular, moldada pelas concepções do bem. Estas identidades, por sua vez, delimitariam os campos constituídos, por um lado, pelos direitos políticos

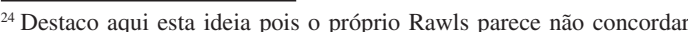
com a ideia de que a sua teoria se sustenta em um duplo estágio de justificação. Essa questão ficará clara na resposta do autor às críticas de Habermas.

${ }^{25}$ No original: "For the higher the veil of ignorance is raised and the more Rawls's citizens themselves take on real flesh and blood, the more deeply they find themselves subject to principles and norms that have been anticipated in theory and have already become institutionalized beyond their control".
}

de participação e, por outro, pelos direitos liberais básicos. A proteção das liberdades privadas desfrutaria de primazia, enquanto os direitos políticos seriam prioritariamente meios de proteção dessas outras liberdades. Tal divisão a priori das esferas pública e privada contrasta tanto teoricamente com a intuição republicana segundo a qual a soberania popular e os direitos humanos são nutridos pela mesma fonte, quanto empiricamente com o fato de que a posição cambiante da linha que as separa sempre constitui-se como um problema normativo ${ }^{26}$ - o desenvolvimento do estado de bem-estar, ademais, acentua o caráter instável desta separação e mostra a importância de que ela seja submetida à formação política da vontade, especialmente se a autonomia pública deve ser capaz de pressionar pela garantia do valor equitativo das liberdades políticas.

Portanto, Habermas (1995) entende que, no projeto rawlsiano, o filósofo está em uma posição da qual determina, monologicamente, qual deve ser o resultado do discurso ideal. O processo democrático deliberativo encontra-se relegado a uma posição inferior e não desfruta do potencial de gerar leis legítimas. A isto ele se opõe, pois considera inaceitável que qualquer representação simplificada dos participantes deste discurso possa ser fonte de legitimidade. Para se contrapor ao que concebe como uma separação entre autonomia pública e privada, Habermas sugere que uma análise adequada da questão leva inevitavelmente à compreensão de que elas são cooriginárias:

A relação dialética entre autonomia pública e privada torna-se clara sob a luz do fato de que o status destes cidadãos democráticos, a quem foram conferidas as competências de legislar, só poderá ser institucionalizado por meio da lei (coercitiva). Mas porque essa lei é dirigida a pessoas que não podem sequer assumir o status de sujeitos legais sem direitos privados subjetivos, a autonomia pública e privada dos cidadãos pressupõem-se mutuamente (Habermas, 1995: 130, tradução livre $)^{27}$.

Ambos os elementos estariam, em verdade, entrelaçados, pois não poderia existir uma lei

\footnotetext{
${ }^{26}$ As teorias feministas da política foram importantes para esclarecer esse ponto. O próprio Habermas admitiu modificações significativas em sua teoria a partir das críticas feitas por autoras como Iris Young, Nancy Fraser e Seyla Benhabib. Cf. Benhabib (1996).

${ }^{27}$ No original: "The dialectical relation between private and public autonomy becomes clear in light of the fact that the status of such democratic citizens equipped with law-making competences can be institutionalized in turn only by means of coercive law. But because this law is directed to persons who could not even assume the status of legal subjects without subjective private rights, the private and public autonomy of citizens mutually presuppose each other".
} 
legítima sem liberdades subjetivas contestáveis, que garantam a autonomia privada de sujeitos legais individuais; da mesma forma, não é possível haver leis legítimas sem a legislação democrática dos cidadãos em comum, que, em seu status de pessoas morais livres e iguais, têm o direito de participar do processo de autodeterminação. Uma vez que se entende a concepção de lei dessa forma, parece claro que a substância normativa dos direitos liberais está contida no meio para a institucionalização legal do uso público da razão. Torna-se premente, então, analisar os pressupostos comunicativos e os processos discursivos de formação democrática da opinião e da vontade, nos quais se manifesta o uso público da razão.

Esse caminho, baseado em sua própria ética do discurso, seria, segundo Habermas, ao mesmo tempo mais e menos modesto do que o projeto rawlsiano. Mais modesto por focar exclusivamente os aspectos procedimentais do uso público da razão e por derivar o sistema de direitos da ideia de sua institucionalização legal. Além disso, ele deixa mais questões em aberto, pois confia mais no processo de formação da opinião e da vontade de cidadãos livres e racionais. Essa proposta, portanto, pesa menos os ombros do filósofo, uma vez que não cabe a ele elaborar a ideia de uma sociedade justa a partir da qual os cidadãos irão julgar os arranjos institucionais e as políticas públicas. Na proposta de Habermas, cabe ao filósofo elaborar o ponto de vista moral e o processo de legitimação democrática para a análise das condições de possibilidade do discurso racional. A filosofia, nesse modelo, procede menos de forma construtiva do que reconstrutiva. Ela deixa questões substantivas para serem respondidas aqui e agora pelo engajamento mais ou menos ilustrado dos cidadãos. O que, contudo, não isenta o filósofo de participar do debate público, embora no papel de intelectual, e não de especialista (Habermas, 1995: 131).

\section{III}

Em sua resposta às críticas que lhe foram dirigidas por Habermas, Rawls identifica alguns equívocos na leitura feita pelo autor alemão. Reconhece, no entanto, a necessidade de tornar mais nítido o lugar do uso público da razão em seu projeto teórico, bem como explicitar o seu entendimento sobre as características do processo democrático em relação aos princípios de justiça. Nesse caminho, Rawls apresenta as diferenças entre os dois projetos teóricos, mas deixa transparecer uma concepção de democracia que os aproxima na mesma medida.

\section{III.1}

Para estabelecer uma distinção clara entre a justiça como equidade e as ideias associadas ao liberalismo político, de um lado, e a teoria do discurso, de outro, Rawls (2011a) apresenta duas diferenças fundamentais. A primeira diferença básica se relaciona ao estatuto filosófico de cada uma: enquanto Habermas teria formulado uma filosofia abrangente, Rawls procura construir uma teoria do político, que esteja restrita a este âmbito e deixe intocada a filosofia. A segunda se relaciona aos dispositivos de representação - a saber, a posição original e a situação ideal de fala -, seus objetivos e papéis, assim como as suas características e finalidades.

O liberalismo político, como o concebe Rawls, recai sob a rubrica do político e consiste em concepções políticas do direito e da justiça que se sustentam por si mesmas (freestanding). Nesse projeto, é fundamental que a filosofia não faça referência a (ou ao menos não dependa de) qualquer doutrina, seja ela religiosa, moral ou metafísica. É o que o autor afirma abaixo.

Concebo a justiça como equidade como se propondo desenvolver uma concepção política liberal de justiça para um regime democrático, uma concepção que poderia ser endossada - esta é a aspiração - por todas as doutrinas abrangentes razoáveis que existiriam em uma democracia que fosse regulada por ela ou por alguma concepção similar (Rawls, 2008: 142).

A teoria habermasiana, por sua vez, seria uma filosofia abrangente e abarcaria elementos de vários campos adjacentes à filosofia propriamente política. A teoria da ação comunicativa teria o intuito de oferecer uma teoria geral que se aplique tanto à razão teórica como às diferentes formas de razão prática. A partir da necessidade de uma fundamentação das formas básicas de ação que vá além delas mesmas, os cidadãos buscariam, em pensamento, alcançar o que está por trás de doutrinas abrangentes ou o que poderiam considerar um fundamento mais forte para a ação. No projeto habermasiano, a única alternativa nessa procura é o procedimento democrático, cujo significado reside no sistema de direitos.

Segundo Rawls, a lógica dessa substituição seria metafísica, pois propõe interpretar o mundo a partir de proposições fundamentais e plenamente gerais. $\mathrm{Na}$ posição original, inversamente, formula-se uma conjectura segundo a qual os princípios mais razoáveis de justiça política para uma sociedade democrática poderiam ser fornecidos valendo-se de uma argumentação moral que apresenta um dispositivo de representação em que as partes 
racionais (que representam os cidadãos) escolhem princípios de justiça para uma sociedade democrática bem-ordenada, sob restrições impostas pelo contexto. Essa situação é formulada de modo que os próprios cidadãos, em sua condição de liberdade e igualdade, possam chegar eles mesmos a um acordo sobre os princípios de justiça, "sob condições que os representam como pessoas tanto razoáveis quanto racionais". Mas que estes serão, de fato, os princípios mais razoáveis é uma conjectura que, evidentemente, pode mostrar-se incorreta. Nesse sentido, eles são confrontados com outros pontos do juízo ponderado dos cidadãos, assim como são testadas a sua adequação às instituições de uma sociedade democrática, os seus resultados etc. (Rawls, 2011a: 450-1).

Ao comparar os dispositivos de representação - a posição original e a situação ideal de fala - Habermas teria cometido um equívoco, pois considerou que os lugares em que se situam e o ponto de onde falam os dois modelos seriam distintos: a justiça como equidade seria uma posição de autoridade filosófica sobre a autolegislação dos cidadãos, enquanto a teoria do discurso deixaria a cargo destes a formulação e a aceitação dos princípios de justiça. Segundo Rawls (2011a), no entanto, em ambos os casos as discussões partem do ponto de vista do cidadão, situado naquilo que Habermas denomina de esfera pública. É dessa posição que os cidadãos de uma sociedade qualquer avaliam a formulação dos princípios da justiça como equidade, se e quais aspectos são válidos ou devem ser modificados. Dessa mesma posição examinam as pretensões da teoria do discurso, sempre sobre o pano de fundo da "cultura da vida cotidiana", sob a influência de várias instituições e das inesgotáveis discussões políticas. A justiça como equidade, assim como a ética do discurso, se dirige aos cidadãos e seu objetivo último é ser apresentada à sociedade civil e ser por ela compreendida e aceita (Rawls, 2011b: 454-5).

\section{III.2}

Habermas incorre em um segundo equívoco quando entende o consenso sobreposto como um segundo passo na justificação da justiça como equidade. $\mathrm{O}$ autor alemão indaga se o consenso sobreposto acrescenta algo à justificação de uma concepção política de justiça que já é considerada razoável, ou melhor, ele questiona em que medida as doutrinas que se incluem nesse consenso fortalecem a justificação ou se se apresentam apenas como condição necessária à estabilidade social. A resposta a essa questão, para Rawls, encontra-se relacionada ao modo como o liberalismo político distingue três formas de justificação e dois tipos de consenso.

A primeira forma de justificação, que Rawls (2011a) denomina "pro tanto", considera apenas os valores políticos. Estes podem ser ordenados de forma que bastem, como resposta razoável, mediante a razão pública, a todas as decisões relacionadas aos princípios constitucionais essenciais e às questões de justiça básica. Ao avaliar as diversas controvérsias de natureza política e a adequação de uma concepção política para oferecer respostas apropriadas a elas, é possível perceber em que medida ela seria completa nesse sentido. Contudo, por ser uma justificação pro tanto, é possível que as doutrinas abrangentes se superponham a ela quando todos os valores forem levados em conta.

A segunda forma, a justificação plena, é realizada pelo cidadão individual, membro da sociedade civil. Cada cidadão aceita uma concepção política de justiça, cuja justificação ele completa inserindo-a em sua doutrina abrangente, seja como uma concepção verdadeira, seja como uma concepção razoável.

A terceira forma, a justificação pública, é levada a cabo pela sociedade política, operando em conexão com a ideia do consenso sobreposto razoável, da estabilidade pelas razões certas e da legitimidade. Ao considerarem uns aos outros como pessoas que endossam a concepção política de justiça, os cidadãos moldam a qualidade moral da cultura pública da sociedade política. Assim, embora a concepção política dependa indiretamente das doutrinas abrangentes, seu conteúdo normativo não depende delas, limitando-se, portanto, ao âmbito do político. A justificação pública só é possível quando há um consenso sobreposto razoável.

Esse caso fundamental de justificação pública é aquele no qual a concepção política de justiça compartilhada constitui o terreno comum e todos os cidadãos razoáveis considerados coletivamente (mas não agindo como corpo coletivo) conservam-se em um estado de equilíbrio reflexivo amplo e geral, ao afirmarem a concepção política com base em suas diferentes doutrinas abrangentes razoáveis (Rawls, 2011a: 458-9).

A justificação se encontra, por sua vez, relacionada a duas formas de consenso. Uma ideia usual de consenso é aquela proveniente do jogo político ordinário, no qual os políticos se empenham em formular uma política pública (ou um programa político) que possa desfrutar do apoio de todos ou ao menos de uma maioria suficiente. Tal ideia pressupõe que haja uma área de acordo, presente ou latente, que poderá ser construída no jogo político pela articulação de interesses. Já no consenso sobreposto 
razoável do liberalismo político, articula-se uma concepção política de justiça que se sustenta por si mesma e que pode ser justificada pro tanto. Para que todas as doutrinas abrangentes possam subscrever tal concepção, ela não pode envolver ideias que vão além do político, pois recorrer a essas ideias viola a exigência de reciprocidade. Sustentar a possibilidade de um consenso desse tipo, que seja apoiado pelas razões certas, também faz parte da justificação pública. Dado o fato do pluralismo razoável, a possibilidade de um consenso sobreposto a respeito de uma concepção política de justiça torna-se uma maneira importante de avaliar se a justiça como equidade poderá ser defendida sinceramente diante dos demais cidadãos sem que seja necessário rejeitar os seus compromissos religiosos ou morais. O consenso que se forma em tal sociedade propicia a estabilidade (pelas razões certas), interpretada da seguinte forma: (a) a estrutura básica é regulada pela concepção política de justiça mais razoável; (b) a concepção política é apoiada por um consenso sobreposto de todas as doutrinas abrangentes razoáveis existentes na sociedade; e (c) as discussões políticas na esfera pública sobre elementos constitucionais essenciais e questões de justiça básica podem ser decididas, de forma razoável, em referência às razões especificadas por tal concepção política de justiça $^{28}$.

Assim, a resposta à questão, colocada por Habermas, em relação à ideia de consenso sobreposto - se ele está incluído na justificação da concepção política ou se meramente estabelece uma condição necessária à estabilidade social - se encontra na ideia de justificação pública, articulada ao consenso sobreposto razoável, à estabilidade pelas razões certas e à legitimidade (Rawls, 2011a: 465-6). A justificação, nesse sentido, não pode ser uma questão de aceitabilidade no sentido habermasiano, que envolve a "redenção" de reivindicações de validade cognitivas presentes no discurso. Ela está relacionada a uma forma de aceitação por razões abrangentes, embora sem que se exija que todos aceitem pelas mesmas razões - algumas (políticomorais) são compartilhadas, enquanto outras (ligadas às doutrinas abrangentes) variam de um cidadão para o outro. Rawls não pergunta se o consenso sobreposto justificaria a concepção política de justiça, dando a

\footnotetext{
${ }^{28}$ Uma sociedade não desfrutaria de uma estabilidade pelas razões certas quando as concepções políticas dos cidadãos não se inserem em uma concepção política compartilhada - ou quando os cidadãos são agrupados de acordo com as suas justificações plenas. Nesse caso, diz-se que a sociedade representa tão somente um modus vivendi, cuja estabilidade social depende de um equilíbrio contingente de forças, frequentemente sujeito a alterações e mudanças bruscas (Rawls, 2011a: 461).
}

ela caráter de verdade ou validade. Antes, ele indaga acerca da possibilidade de que tal consenso seja obtido (Finlayson e Freyenhagen, 2011). Para Rawls (2011a: 514), a teoria normativa pertence à "arte do possível". Como tal, ela deve considerar aquilo que é factível, embora haja formas distintas de fazê-lo.

\section{III.3}

Como visto na segunda parte deste trabalho, Habermas entende que o fato de Rawls derivar as liberdades individuais e os direitos de participação de um mesmo fundamento (ambos se encontram no primeiro princípio de justiça), impede que as primeiras sejam constrangimentos externos ao processo de autodeterminação política dos cidadãos. Ele acredita, no entanto, que a formulação da justiça como equidade, começando pela posição original para chegar à aplicação de fato dos princípios à sociedade política, faz com que os direitos liberais assumam uma primazia que rebaixa o processo democrático a um status inferior. $\mathrm{O}$ fato de conferir à autonomia política uma existência virtual na posição original implicaria em um desenvolvimento deficitário da mesma na sociedade política real. Ademais, como os princípios de justiça seriam dados de antemão, a fundação da Constituição democrática estaria impedida de se repetir, o que tornaria impossível a garantia de que o processo de realização dos direitos fundamentais seja permanente-ou, em suas palavras, que se mantivessem acesas as brasas democráticas.

Todavia, esta não parece ser uma interpretação adequada da sequência de quatro estágios formulada na teoria de justiça como equidade ${ }^{29}$. Essa sequência faz parte de uma estrutura de deliberação que é usada pela justiça como equidade para defender seus conceitos e princípios. Ela expõe as normas e informações que devem guiar os juízos políticos de justiça em cada contexto específico. Dessa forma, cada estágio conta com um grau de informação, cujo intuito é oferecer aos cidadãos as condições necessárias à aplicação dos princípios de justiça, vedando as decisões que favoreçam interesses específicos vinculados às doutrinas abrangentes a que eventualmente venham a se filiar.

\footnotetext{
${ }^{29}$ Nas palavras de Rawls: "Começamos na posição original, na qual as partes escolhem os princípios de justiça. A seguir passamos a uma convenção constitucional na qual - concebemo-nos como delegados - temos de formular os princípios e as normas de uma Constituição à luz dos princípios de justiça que já estão à mão. Depois disso, por assim dizer, tornamo-nos legisladores que aprovam leis de acordo com a Constituição e segundo os princípios de justiça o exijam e permitam. Por fim, assumimos o papel de juízes que interpretam a Constituição e as leis como membros do Judiciário" (2011a: 470).
} 
Portanto, as instituições sob as quais se encontram os cidadãos em uma sociedade não são obra da intuição de um filósofo político que as institui fora do controle dos que a ela se submetem - o que relegaria os cidadãos a uma condição heterônoma. Antes, elas são fruto de gerações anteriores, e deverão ser avaliadas e eventualmente modificadas a partir dessa condição. Seria um equívoco, portanto, supor que o emprego de uma situação original hipotética constituiria uma escolha de princípios que valham para todo o sempre. Imaginar isso seria, segundo Rawls, desconsiderar que a concepção política de justiça, como de resto qualquer outra concepção de justiça, estará sempre sujeita aos juízos ponderados de todos os cidadãos. Além disso, a autonomia é um atributo político e se expressa nas discussões e deliberações dos cidadãos em um regime constitucional. Como visto na seção I, os cidadãos estão continuamente debatendo questões que envolvem os princípios de justiça e as políticas públicas. Nenhuma teoria é capaz de prever todas as circunstâncias e as reformas necessárias para sanar injustiças decorrentes dos arranjos institucionais reais. $\mathrm{E}$ a teoria da justiça como equidade não é diferente, nem arroga sê-lo.

Ao supor que a justiça como equidade não permite a realização da autonomia política, Habermas (1995) sustenta que a autonomia política consiste na elaboração da Constituição pelos cidadãos, mediante seus debates fundamentais e discursos essenciais de legitimação - assim como na construção de todas as normais legais de nível inferior que se aplicarão a eles. Na perspectiva rawlsiana, a autonomia política dos cidadãos será plena na medida em que vivam sob uma Constituição justa, sob normas legais de nível inferior que se aplicam à estrutura básica, quando compreendem e acatam tal Constituição e suas leis, assim como podem alterá-las conforme as circunstâncias o exijam. Por outro lado, caso a Constituição e as leis sejam injustas, os cidadãos têm boas razões para lutar por sua modificação, de modo que seja atribuído um valor equitativo às suas liberdades políticas. É dessa maneira que Rawls concebe a Constituição: nos termos de Habermas, como um projeto inacabado (Rawls, 2011a: 473-7).

\section{III.4}

Contudo, persiste ainda a questão envolvendo a distinção entre as identidades pública e privada dos cidadãos, que, segundo Habermas (1995), seria fonte de restrição ao exercício das liberdades políticas e da autodeterminação. As distintas identidades delimitariam os direitos de participação e comunicação política, de um lado, e os direitos liberais, de outro - sendo atribuída primazia a estes últimos, enquanto os primeiros seriam apenas instrumentos para a proteção das liberdades fundamentais. $\mathrm{Na}$ crítica de Habermas, o domínio privado seria, no projeto rawlsiano, imune à autolegislação. No entanto, Rawls se opõe a esta visão, ressaltando que, já em Uma Teoria da Justiça, chama atenção para o fato de as liberdades políticas constituírem parte fundamental da vida de algumas pessoas e das bases sociais do autorrespeito - o primeiro princípio de justiça e a sua concepção de pessoa moral deixam claro a cooriginalidade das autonomias pública e privada. Ademais, o estágio de construção constitucional, no qual é feita a escolha, com base nos princípios de justiça, da Carta de Direitos que limita a legislação majoritária (impedindo-a, por exemplo, de vedar as liberdades de expressão e de imprensa) não se dá em um nível pré-político. De acordo com Rawls, "[v]alores não-políticos não são considerados [...] ontologicamente prévios e, por esta razão, prévios a valores políticos". A justiça como equidade permite, embora não exija, que as liberdades fundamentais constem na Carta Constitucional. Subscrever uma Constituição, portanto, que limita a autolegislação democrática não é algo que se dá em um nível pré-político e não representa, dessa forma, limite externo à vontade democrática (Rawls, 2011a: 478-9).

Nesse sentido, a justiça como equidade é plenamente compatível com a forma de soberania popular valorizada por Habermas. O processo constituinte no projeto rawlsiano não fica relegado às considerações da filosofia política, ele depende dos arranjos institucionais e de uma compreensão adequada de sua operação. Sendo assim, poder-se-ia afirmar, como o faz Rawls, que em ambas as teorias a decisão por incorporar à Constituição os direitos liberais é uma decisão a ser tomada a posteriori, via deliberação pública (Rawls, 2011a: 487-91).

Na justiça como equidade não existem especialistas filósofos. Deus nos livre disso! Mas afinal de contas, os cidadãos devem ter algumas ideias sobre direito e justiça em seu pensamento e devem contar com alguma base para sua reflexão sobre essas questões. Aqueles que estudam filosofia participam da formulação dessas ideias, mas sempre na condição de cidadãos como todos os demais (Rawls, 2011a: 506).

\section{À Guisa de Conclusão}

As questões discutidas até aqui permitem afirmar que, embora se afastem em muitos pontos, os projetos teóricos de Rawls e Habermas guardam pontos de 
contato. $\mathrm{O}$ próprio autor alemão parece admitir isso ao afirmar, na introdução de seu texto de 1995, que o seu debate com Rawls era uma controvérsia familiar. No texto que aqui se conclui, foram apresentadas as respostas destes autores a questões tão espinhosas como a possibilidade de justificação política em um contexto de pluralismo razoável, a ideia de legitimidade democrática e a relação entre moralidade, democracia e justiça.

A distinção mais fundamental entre as elaborações normativas de Rawls e Habermas se refere à justificação de uma democracia deliberativa e às características da razão pública. Enquanto na teoria discursiva habermasiana a deliberação se apresenta como a melhor forma de encontrar a verdade sobre a lei racional que promove a justiça, na abordagem rawlsiana não se confere caráter epistêmico à deliberação pública - em Rawls, a deliberação é um requisito moral da legitimidade política e uma das formas em que se materializa a garantia do valor equitativo das liberdades políticas (Freeman, 2000: 378). Seria possível, de acordo com McCarthy, entender a leitura habermasiana sobre questões políticas e sociais como um prolongamento das pré-condições psicológicas, culturais e institucionais da, bem como das barreiras à, implementação de discursos práticos (1994: 47-8). Nesse caso, para levar em conta certas críticas feitas por Habermas, especialmente quando este considera que o ponto de vista moral se encontraria implícito nas práticas de argumentação pública, Rawls teria de aceitar as premissas de uma filosofia da linguagem, o que não aparece no horizonte de um projeto teórico que pretende desenvolver uma concepção política de justiça que se sustenta por si mesma - que aplica à filosofia o princípio da tolerância ${ }^{30}$.

A distância entre os autores que se verifica nesse ponto, contudo, não compromete uma aproximação no que concerne à característica central do ideal deliberativo, qual seja, a necessidade de justificação pública do exercício do poder coercitivo da sociedade. Embora Habermas tenha uma visão mais ampla do alcance da argumentação pública no processo de justificação e procure delinear uma forma processual mais direta para a democracia deliberativa, Rawls (2003; 2008) também considera que a dimensão

\footnotetext{
${ }^{30}$ Segundo Rouanet, enquanto Habermas "espera demais da comunicação entre os diversos atores da sociedade, descartando o entendimento em um nível superior, Rawls, ao exigir menos dos cidadãos, "ou antes, contando com seu egoísmo racional, de certa maneira resolve o problema de Rousseau, e de Kant, de como dar um governo mesmo a um povo de demônios. E o faz renunciando a uma exigência de fundamentação última, abandonando ao mesmo tempo o olhar de sobrevoo do pássaro hegeliano, e descendo à terra” (2005: 8).
}

pública dos problemas que envolvem princípios constitucionais essenciais e questões de justiça básica esteja sujeita às injunções da razão pública ${ }^{31}$. Ademais, Habermas parece aproximar-se de Rawls em uma obra como Verdade e Justificação, especialmente no que se refere à relação entre a filosofia e o mundo real (Rouanet, 2005).

Já em Direito e Democracia, Habermas (1997) aborda a questão da legitimidade política, ou as condições sociais e institucionais que possibilitam a realização da lei legítima. Para ele, seriam condições necessárias: o Estado representativo democrático, o Estado de Direito e uma sociedade civil (i.e. esferas públicas autônomas nas quais circula livremente o discurso público) apoiada em um sistema de direitos individuais. Tais condições, inter-relacionadas, manteriam acesas as brasas democráticas, uma vez que a soberania popular e os direitos liberais são reciprocamente exigidos e cooriginários. Rawls (2011b), por sua vez, n'O Liberalismo Político, indaga sobre as condições de possibilidade de uma sociedade justa e estável, de cidadãos livres e iguais, separados por doutrinas abrangentes razoáveis. Não surpreende, portanto, que considere como condições necessárias: o Estado representativo democrático, o Estado de Direito e um sistema de direitos individuais, embora no caso de Rawls foco recaia menos sobre a institucionalização dos mesmos do que sobre a concepção de justiça que poderia guiar e julgar tal institucionalização.

Além disso, parece claro que tanto Rawls (2011a) quanto Habermas (1995) consideram as práticas deliberativas não apenas como uma etapa anterior à decisão política, mas como uma discussão cujo foco é a justificação das decisões baseada em uma concepção do bem comum. Apostam, assim, na capacidade do discurso de levar ao entendimento mútuo entre os cidadãos, pois estes, no uso público da razão, mobilizam argumentos não apenas no intuito de tornar públicos os seus interesses, mas se veem compelidos a levantar argumentos que possam ser aceitos - ou não rejeitados - como razoáveis por todos.

Nesse sentido, é fundamental compreender a distinção entre argumentação e discussão pública, pois uma versão deliberativa da democracia não se configura apenas como uma ênfase na discussão em detrimento da barganha ou do voto como mecanismos de decisão coletiva. O conceito de democracia deliberativa, de acordo com as concepções de Rawls (2011a) e Habermas (1995), consubstancia

\footnotetext{
${ }^{31}$ Para Rawls, portanto, apenas as questões políticas relacionadas às bases de legitimidade do sistema merecem tratamento diferenciado e estão sujeitas aos critérios da razão pública. Cf. Rawls (2008).
} 
um sistema de arranjos políticos e sociais que liga institucionalmente o exercício do poder político à argumentação pública entre iguais. É, portanto, crucial aos dois projetos teóricos um princípio de justificação discursiva, i.e., qualquer instituição que pretenda assentar-se em princípios de justiça válidos recíproca e geralmente deve submeter-se ao discurso público levado a cabo pelos cidadãos, considerados pessoas livres e iguais. Ainda que estes princípios sejam construídos teoricamente, eles só poderão arrogar o status de validade se discursivamente aceitos.

Nessa concepção, a exigência de mútuo respeito entre os cidadãos não se manifesta na ideia de igual consideração pelo interesse de todos, mas no oferecimento de justificações para o exercício do poder coletivo que possam ser aceitas razoavelmente por todos como razões legítimas. O reconhecimento do "fato do pluralismo razoável" torna obrigatório que as decisões coletivas sejam sustentadas por razões que possam ser aceitáveis por todos os membros de uma associação política, sobretudo quando as decisões envolvem um componente de desacordo moral, independentemente da concepção abrangente de bem a que cada cidadão adira (Araújo, 2004: 159-60).

Na concepção compartilhada por Rawls (2011a) e Habermas (1995), a democracia deve assegurar as liberdades dos modernos, como as religiosas, expressivas e morais. Essa afirmação contrasta com o entendimento expresso pelo autor alemão em sua crítica publicada no Journal of Philosophy. Em ambos os projetos teóricos a lógica que subjaz à proteção das liberdades dos modernos não é nem estritamente política, nem antipolítica. Não é política em uma concepção restrita, pois não se refere apenas à oportunidade de participação das pessoas na política regular, nem tampouco a um instrumento para aprimorar a discussão pública mediante a inclusão de outras vozes a ela. Não é antipolítica, tampouco, pois não tem por objetivo simplesmente assegurar o poder de associações e organizações, como as igrejas, que ajudam a proteger os indivíduos do Estado. O argumento é o de que restrições a essas liberdades comprometem a posição dos cidadãos como membros iguais do povo soberano, pois impõem a rejeição de razões que, à luz de suas concepções do bem, parecem convincentes (Cohen, 1998: 206-7).

Portanto, na concepção teórica comum aos dois autores, as liberdades são justificadas tanto porque garantem aos cidadãos as oportunidades para defenderem seus interesses na arena decisória quanto porque delimitam um campo que os protege de decisões coletivas que eventualmente os proíbam de expressar suas diferentes filosofias, estilos e formas de vida compatíveis com a vida comum. Pois tais decisões, se aprovadas, teriam de ser justificadas por razões que nem todos considerariam aceitáveis.

Destarte, ao contrário do que afirma Rouanet (2005: 9), para quem "[...] a teoria de Rawls poderia beneficiar-se de um maior grau de concretude operacional ao incorporar elementos da teoria da ação comunicativa [...]", argumenta-se que o liberalismo político já incorpora o elemento argumentativo em uma teoria da democracia que subjaz ao projeto mais amplo de uma concepção política de justiça. A carência de uma ênfase maior sobre o processo político democrático está assentada, por sua vez, na própria natureza de uma teoria que se concentra no aspecto político e pretende formular uma concepção política de justiça que se sustente por si mesma. Da mesma forma, os que acusam a infactibilidade do desafio deliberativo habermasiano carecem da sensibilidade necessária à percepção do caráter crítico-normativo - oposto ao explicativo - de sua teoria. Em Habermas (1997), a crítica da razão deixa de ser uma forma de subjetividade transcendental para tornar-se uma forma de comunicação. Para Habermas, a validade está amarrada ao acordo razoável sobre reivindicações contestáveis. Nos dois casos, a concepção deliberativa da democracia é menos um conceito explanatório do que uma contribuição aos ideais de democracia e justiça (Freeman, 2000: 373). Cabe àqueles que se debruçam sobre o projeto teórico destes autores, cientistas políticos ou filósofos da política, levarem adiante as implicações teóricas e práticas desta valiosa obra para as democracias contemporâneas.

\section{Referências}

Araújo, Cícero. 2004. "Razão Pública, Bem Comum e Decisão Democrática”. In V. S. P. Coelho e M. Nobre (orgs.) Participação e Deliberação: Teoria democrática e experiências institucionais no Brasil contemporâneo. São Paulo: Editora 34, p. 157-72.

Benhabib, Seyla. 1996. Democracy and Difference: Contesting the Boundaries of the Political. Princeton: Princeton University Press. PMid:12321188.

Cohen, Joshua. 1998. Democracy and Liberty. In J. Elster (ed.), Deliberative Democracy. Cambridge: Cambridge University Press, p. 185-231. http://dx.doi. org/10.1017/CBO9781139175005.010

Cohen, Joshua. 2003. For a democratic society. In S. Freeman (org.), The Cambridge Companion to Rawls. Cambridge: Cambridge University Press, p. 86-138.

Freeman, S. 2000. Deliberative democracy: a sympathetic comment. Philosophy and Public Affairs, 29(4): 371-418. http://dx.doi. org/10.1111/j.1088-4963.2000.00371.x 
Finlayson, James Gordon e Freyenhagen, Fabian. 2011. Introduction: The Habermas-Rawls Dispute - Analysis and Reevaluation. In Finlayson, J.G. \& Freyenhagen, F. (eds.). Habermas and Rawls: Disputing the Political. New York: Routledge.

Gutmann, Amy e Thompson, Dennis F. 2004. Why Deliberative Democracy? Princeton: Princeton University Press.

Habermas, Jürgen. 1995. Reconciliation Through the Public use of Reason: Remarks on John Rawls's Political Liberalism. Journal of Philosophy, 92(3): 109-131. http://dx.doi.org/10.2307/2940842

Habermas, Jürgen. 1997. Direito e Democracia: entre facticidade e validade. vol. 2. Rio de Janeiro: Tempo Brasileiro.

McCarthy, Thomas. 1994. Kantian Constructivism and Reconstructivism: Rawls and Habermas in Dialogue. Ethics, 105(1): 44-63. http://dx.doi.org/10.1086/293678

Nagel, Thomas. 2003. Rawls and Liberalism. In S. Freeman (org.). The Cambridge Companion to Rawls. Cambridge: Cambridge University Press, p. 62-85.

Przeworski, Adam. 2010. Democracy and the Limits of Self-Government. New York: Cambridge University Press. http://dx.doi.org/10.1017/CBO9780511778490

Rawls, John. 2003. Justice as Fairness - a reestatement. Erin Kelly (ed.). Cambridge, Mass.: The Belknap Press of Harvard University Press.
Rawls, John. 2008. Uma Teoria da Justiça. 3 ed. Jussara Simões(trad.). São Paulo: Martins Fontes.

Rawls, John. 2011a. Resposta a Habermas. In J. Rawls. $O$ Liberalismo Político. Álvaro de Vita (trad.). ed. ampl. São Paulo: Editora WMF Martins Fontes, p. 440-515.

Rawls, John. 2011b. A ideia de razão pública revisitada. In J. Rawls. O Liberalismo Político. Luís Carlos Borges (trad.). ed. ampl. São Paulo: Editora WMF Martins Fontes, p. 519-83.

Rouanet, Luiz Paulo. 2005. A complementaridade entre Rawls e Habermas na etapa da deliberação. Campinas: Universidade São Marcos: PUC.

Sandel, Michael. 1982. Liberalism and the Limits of Justice. Cambridge: Cambridge University Press.

Vita, Álvaro de. 2000a. A Justiça Igualitária e seus Críticos. São Paulo: Editora UNESP.

Vita, Álvaro de. 2000b. Democracia e Justiça. Lua Nova: revista de cultura e política. São Paulo, 50: 5-24.

Vita, Álvaro de. 2008. O Liberalismo Igualitário: Sociedade democrática e justiça internacional. São Paulo: Martins Fontes.

Werle, Denilson. 2004. Democracia deliberativa e os limites da razão pública. In V. S. P. Coelho e M. Nobre (orgs.) Participação e Deliberação: Teoria democrática e experiências institucionais no Brasil contemporâneo. São Paulo: Editora 34, p. 131-56. 